\title{
Rosiglitazone preserves pulmonary vascular function in lambs with increased pulmonary blood flow
}

\author{
Peter E. Oishi', Shruti Sharma², Sanjeev A. Datar', Sanjiv Kumar², Saurabh Aggarwal², Qing Lu², Gary Raff ${ }^{3}$, Anthony Azakie',
} Jong-Hau Hsu', Eniko Sajti', Sohrab Fratz ${ }^{5}$, Stephen M. Black² and Jeffrey R. Fineman'

BACKGROUND: Pulmonary vascular function is impaired with increased pulmonary blood flow (PBF). We hypothesized that a peroxisome proliferator-activated receptor- $\gamma$ (PPAR- $\gamma$ ) agonist would mitigate this effect.

METHODS: An aorta-to-pulmonary-artery shunt was placed in 11 fetal lambs. Lambs received the PPAR-y agonist rosiglitazone $(\mathrm{RG}, 3 \mathrm{mg} / \mathrm{kg} / \mathrm{d}, n=6)$ or vehicle $(n=5)$ for $4 \mathrm{wk}$. Lung tissue from five normal 4-wk-old lambs was used for comparisons.

RESULTS: At 4 wk, pulmonary artery pressure (PAP) and vascular resistance (PVR) decreased with inhaled nitric oxide (NO) in RG- and vehicle-treated shunt lambs. PAP and PVR decreased with acetylcholine (Ach) in RG-treated, but not vehicle-treated, shunt lambs. In vehicle-treated shunt lambs, nicotinamide adenine dinucleotide phosphate (NADPH) oxidase activity, rac1, superoxide, and 3-nitrotyrosine (3-NT) levels were increased, and Ser1177 endothelial NO synthase (eNOS) protein was decreased as compared with normal lambs. In RG-treated shunt lambs, NOx, Ser1177 eNOS protein, and eNOS activity were increased, and NADPH activity, rac1, superoxide levels, and 3-NT levels were decreased, as compared with vehicle-treated shunt lambs. PPAR-y protein expression was lower in vehicle-treated shunt lambs than in normal and RG-treated shunt lambs.

CONCLUSION: The PPAR-y agonist RG prevents the loss of agonist-induced endothelium-dependent pulmonary vascular relaxation in lambs with increased PBF, in part, due to decreased oxidative stress and/or increased NO production.

nfants and children with congenital cardiac defects that cause increased pulmonary blood flow (PBF) are at risk for developing pulmonary vascular disease. In fact, even early pulmonary vascular dysfunction, with abnormal vascular reactivity, causes significant morbidity and mortality in these patients. A decrease in bioavailable nitric oxide (NO), in part, due to oxidative stress, is known to contribute to this pathology (1-3).

Peroxisome proliferator-activated receptors (PPARs), members of a nuclear hormone receptor superfamily, are rapidly emerging as integral mediators of a wide array of disease processes, including vascular disorders (4). Although investigations of the vasculature have focused primarily on the systemic circulation, one study found that PPAR- $\gamma$, one of the three PPAR subclasses, was decreased in lung tissue taken from patients with severe pulmonary arterial hypertension (5). The mechanisms by which PPAR- $\gamma$ may affect the development of pulmonary vascular disease are not fully understood. However, expanding data indicate that the loss of PPAR- $\gamma$ may result in perturbations of a number of factors that affect the pulmonary vasculature (6). For example, in recent studies, PPAR- $\gamma$ ligands have been shown to increase NO production by endothelial NO synthase (eNOS), in part, by increasing eNOS activity by a promotion of eNOS phosphorylation at Ser1177, and to decrease reactive oxygen species production through alterations of NADPH oxidase (7-11).

In earlier studies, we investigated alterations in $\mathrm{NO}$ and reactive oxygen species production in the development of pulmonary vascular disease under conditions of increased PBF, using our ovine model of a congenital cardiac defect with increased PBF, created by the in utero placement of an aortopulmonary vascular graft (shunt) (1-3). In the postnatal period, these shunt lambs demonstrated impaired endothelium-dependent relaxation, which was associated with a decrease in bioavailable NO, increased NADPH oxidase subunit expression, increased superoxide production, and increased protein nitration (1-3). Recently, we found that PPAR- $\gamma$ protein expression was decreased in lung tissue taken from 2-wk shunt lambs as compared with healthy age-matched controls, raising the possibility that impaired PPAR- $\gamma$ signaling could contribute to the observed alterations in pulmonary vascular function and $\mathrm{NO}$ signaling (12).

Therefore, the purpose of this study was to test the hypothesis that chronic treatment with the PPAR- $\gamma$ agonist rosiglitazone (RG) would preserve endothelium-dependent pulmonary vascular relaxation, increase bioavailable $\mathrm{NO}$, and decrease markers of oxidative stress in lambs with increased PBF. To this end, shunt lambs were treated from birth until 4 wk of age with enteral RG or vehicle control. At 4 wk of age, pulmonary vascular responses to acetylcholine (ACh), an endotheliumdependent vasodilator, and inhaled $\mathrm{NO}$, an endotheliumindependent vasodilator, were determined, and lung tissue 
was harvested for determinations of bioavailable $\mathrm{NO}(\mathrm{NO} x$ levels), eNOS protein expression and activity, eNOS Ser1177 phosphorylation, NADPH subunit expression ( $\rho$-related C3 botulinum toxin substrate (Rac1), p47 $7^{\text {phox }}$ (phagocytic oxidase), and p67 ${ }^{\text {phox }}$ ) and activity, superoxide levels, and 3-nitrotyrosine (3-NT), an indirect measure of peroxynitrite.

\section{RESULTS}

There were no differences in gestational age, weight, or sex distribution between normal and vehicle- and RG-treated shunt lambs (data not shown). Likewise, baseline hemodynamic variables were not different between vehicle- and RG-treated shunt lambs (Table 1). Baseline hemodynamics and pulmonary vascular reactivity with comparisons between normal and shunt lambs at $4 \mathrm{wk}$ of age have been previously reported (1).

\section{Pulmonary Vascular Reactivity}

Hemodynamic changes in response to $\mathrm{ACh}$ and inhaled $\mathrm{NO}$ in vehicle- and RG-treated shunt lambs are shown in Table 2. Pulmonary artery pressure (PAP) and calculated pulmonary vascular resistance (PVR) did not change in response to ACh in vehicle-treated shunt lambs (Table 2 and Figure 1). In contrast, PAP and calculated PVR decreased in response to ACh in RG-treated shunt lambs $(-18.6 \pm 5.4 \%$ and $-18.2 \pm 7.3 \%$, respectively, $P<0.05$, Table 2 and Figure 1$)$. In response to inhaled NO, PAP and calculated PVR decreased in both vehicle-treated $(-19.3 \pm 6.3 \%$ and $-34.4 \pm 11.6 \%$, respectively, $P<0.05)$ and RG-treated shunt lambs $(-16.1 \pm 4.2 \%$ and -26.4 $\pm 8.2 \%$, respectively, $P<0.05$, Table 2 and Figure 1 ). Changes in PVR in vehicle- and RG-treated shunt lambs in response to $\mathrm{ACh}$ and inhaled NO are shown in Figure 1.

Lung Tissue NOS Activity, NOx, eNOS Protein, and Ser117 Phosphorylation

Lung tissue NOS activity is shown in Figure 2a. Lung tissue NOS activity was greater in RG-treated shunt lambs than in vehicle-treated shunt lambs, and both were greater than in normal lambs $(0.51 \pm 0.28$ vs. $0.22 \pm 0.08$ vs. $0.05 \pm 0.03$ pmol/ $\mathrm{min} / \mathrm{mg}$ protein, respectively, $P<0.05)$. Lung tissue NO $x$ levels were greater in RG-treated shunt lambs than in vehicletreated shunt lambs and normal lambs $(16.9 \pm 8.9 \mu \mathrm{mol} / \mathrm{l} \mathrm{vs}$. $5.7 \pm 3.0$ vs. $4.5 \pm 3.3 \mu \mathrm{mol} / \mathrm{l}$, respectively, $P<0.05$, Figure $2 \mathrm{~b}$ ). $\mathrm{NO} x$ levels relative to NOS activity ( $\mathrm{NO} x / \mathrm{NOS}$ activity ratio) were greater in normal lambs than in vehicle-treated and RG-treated shunt lambs $(P<0.05)$. Lung tissue eNOS protein levels as determined by western blot analysis were not different between groups (data not shown). eNOS phosphorylation at Ser1177 is shown in Figure 2c. eNOS phosphorylation at Ser1177 was lower in vehicle-treated shunt lambs than in normal lambs and RG-treated shunt lambs $(P<0.05)$.

\section{NADPH Oxidase Subunit Expression}

Lung tissue protein levels of $\mathrm{p} 47^{\text {phox }}, \mathrm{p} 67^{\text {phox }}$, and rac1 in normal and vehicle- and RG-treated shunt lambs are shown in Figure $3 \mathrm{a}-\mathrm{c}$ ). Lung tissue protein expression of $\mathrm{p} 47^{\mathrm{phox}}$ was $\sim 20 \%$ greater and expression of p67 ${ }^{\text {phox }}$ was twofold greater in vehicle-treated shunt lambs than in normal lambs, but differences between groups failed to reach statistical significance (ANOVA, $P=0.08$, Figure 3a,b). Lung tissue protein expression of racl was twofold greater in vehicle-treated shunt lambs than in normal lambs, and levels were similar between normal lambs and RG-treated shunt lambs (Figure 3c, ANOVA, $P<0.05$ ).

\section{NADPH Oxidase Activity}

NADPH oxidase activity in lung tissue was higher in vehicletreated shunt lambs than in normal lambs and RG-treated shunt lambs (Figure 4, ANOVA, $P<0.05$ ).

\section{Superoxide Quantitation}

Relative superoxide levels, determined by electronic paramagnetic resonance (EPR) on peripheral lung taken from normal lambs and vehicle- and RG-treated shunt lambs, are shown in Figure 5. Superoxide levels were $\sim 1.75$-fold greater in vehicletreated shunt lambs than in normal lambs (Figure 5a, ANOVA, $P<0.05)$. Superoxide levels were not different between normal lambs and RG-treated shunt lambs (Figure 5a). Specificity of the EPR assay for superoxide was confirmed by a significant reduction in the waveform amplitude in vehicle-treated lambs with the addition of superoxide dismutase to the samples (13). To determine to what extent the contribution of superoxide production arose from NADPH oxidase activity, samples were incubated with apocynin (an NADPH oxidase inhibitor) for $30 \mathrm{~min}$ on ice before the addition of 1-hydroxy-3-methoxycarbonyl-2,2,5,5-tetramethylpyrrolidine $\mathrm{HCl}$ (CM). Apocyninmediated inhibition of NADPH resulted in almost no change in EPR amplitude of normal lambs and RG-treated shunt lambs, whereas vehicle-treated shunt lambs showed up to $\sim 37 \%$ reduction in signal (Figure 5a, $P<0.05$ ).

\section{Protein Nitration}

As an indirect determination of peroxynitrite formation, lung tissue nitrotyrosine (3-NT) levels were determined and are shown in Figure 5b. Lung tissue 3-NT protein expression was greater in vehicle-treated shunt lambs than in normal

Table 1. Baseline hemodynamics

\begin{tabular}{|c|c|c|c|c|c|c|c|c|c|}
\hline Treatment & $\begin{array}{c}\mathrm{HR} \\
\text { (beats/min) }\end{array}$ & $\begin{array}{c}\text { mPAP } \\
(\mathrm{mm} \mathrm{Hg})\end{array}$ & $\begin{array}{l}\text { Syst SAP } \\
(\mathrm{mm} \mathrm{Hg})\end{array}$ & $\begin{array}{l}\text { Diast SAP } \\
(\mathrm{mm} \mathrm{Hg})\end{array}$ & $\begin{array}{c}\text { mSAP } \\
(\mathrm{mm} \mathrm{Hg})\end{array}$ & $\begin{array}{c}\mathrm{Q}(\mathrm{LPA} ; \\
(\mathrm{ml} / \mathrm{min} / \mathrm{kg})\end{array}$ & $\begin{array}{c}\text { RAP } \\
(\mathrm{mm} \mathrm{Hg})\end{array}$ & $\begin{array}{c}\text { LAP } \\
(\mathrm{mm} \mathrm{Hg})\end{array}$ & Qp:Qs \\
\hline Vehicle & $155.8 \pm 27.1$ & $25.0 \pm 3.7$ & $123.0 \pm 18.0$ & $32.1 \pm 7.9$ & $60.8 \pm 6.4$ & $165.5 \pm 51.7$ & $5.4 \pm 1.3$ & $8.5 \pm 2.6$ & $2.74 \pm 0.6$ \\
\hline Rosiglitazone & $124 \pm 24$ & $23.8 \pm 7.4$ & $115.7 \pm 17$ & $41.9 \pm 9.2$ & $62.6 \pm 7.4$ & $128.2 \pm 41.1$ & $5.7 \pm 1.3$ & $6.7 \pm 1.8$ & $2.8 \pm 0.8$ \\
\hline
\end{tabular}

Diast SAP, diastolic systemic arterial pressure; HR, heart rate; LAP, left atrial pressure; LPA, left pulmonary artery; mPAP, mean pulmonary artery pressure; mSAP, mean systemic arterial pressure; Q, flow; Qp:Qs, ratio of pulmonary to systemic flow; RAP, right atrial pressure; Syst SAP, systolic systemic arterial pressure. 
Table 2. Hemodynamic changes in response to $\mathrm{ACh}$ and inhaled nitric oxide

\begin{tabular}{|c|c|c|c|c|}
\hline & Baseline & $\mathrm{ACh}(1 \mu \mathrm{g} / \mathrm{kg})$ & Baseline & iNO (40 ppm) \\
\hline \multicolumn{5}{|l|}{ Vehicle-treated lambs } \\
\hline Mean PAP $(\mathrm{mm} \mathrm{Hg})$ & $25.0 \pm 3.7$ & $21.9 \pm 3.5$ & $25.4 \pm 3.9$ & $20.3 \pm 1.8^{*}$ \\
\hline $\mathrm{LAP}(\mathrm{mm} \mathrm{Hg})$ & $9.5 \pm 2.6$ & $8.0 \pm 1.1$ & $9.7 \pm 2.5$ & $9.6 \pm 2.6$ \\
\hline RAP $(\mathrm{mm} \mathrm{Hg})$ & $5.4 \pm 1.3$ & $6.0 \pm 1.5$ & $5.4 \pm 1.4$ & $4.9 \pm 1.4$ \\
\hline \multicolumn{5}{|c|}{ Rosiglitazone-treated lambs } \\
\hline Mean PAP (mm Hg) & $23.8 \pm 7.4$ & $19.4 \pm 6.6^{*}$ & $24.5 \pm 7.2$ & $20.5 \pm 6.0^{*}$ \\
\hline LPBF (ml/min/kg) & $136.0 \pm 37.5$ & $128.2 \pm 41.1$ & $138.8 \pm 32.1$ & $144.5 \pm 31.0$ \\
\hline LAP $(\mathrm{mm} \mathrm{Hg})$ & $6.7 \pm 1.8$ & $6.5 \pm 1.0$ & $6.8 \pm 3.7$ & $6.4 \pm 3.5$ \\
\hline RAP $(\mathrm{mm} \mathrm{Hg})$ & $5.0 \pm 1.3$ & $5.7 \pm 1.3$ & $5.1 \pm 1.4$ & $4.9 \pm 1.4$ \\
\hline
\end{tabular}

Hemodynamic values before (baseline) and after the administration of ACh and iNO. Values are mean \pm SD.

ACh, acetylcholine; HR, heart rate; iNO, inhaled nitric oxide; LAP, left atrial pressure; LPBF, left pulmonary artery blood flow; PAP, pulmonary arterial pressure; RAP, right atrial pressure.

${ }^{*} P<0.05$ as compared with baseline value.

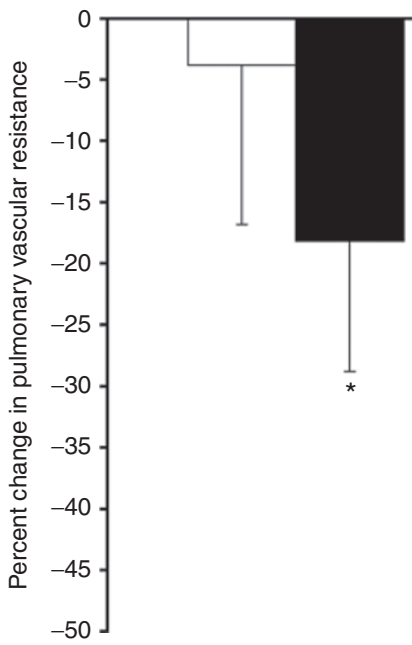

ACh

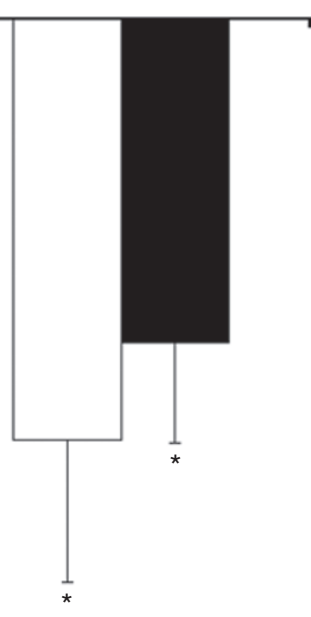

Inhaled NO

Figure 1. Changes in pulmonary vascular resistance (PVR), expressed as percentage change from baseline, in response to acetylcholine (ACh, $1 \mu \mathrm{g} / \mathrm{kg}$ ), an endothelium-dependent agent, and inhaled nitric oxide (NO, 40 ppm), an endothelium-independent agent, in vehicle- and rosiglitazone (RG)-treated shunt lambs. In vehicle-treated shunt lambs (white bars), PVR decreased in response to inhaled NO, but not to ACh. In RG-treated shunt lambs (black bars), PVR decreased in response to both ACh and inhaled NO. $n=6$ for RG-treated group; $n=5$ for vehicle-treated group. Values are mean $\pm \mathrm{SD} .{ }^{*} P<0.05$ as compared with baseline.

lambs and RG-treated shunt lambs (Figure 5b, ANOVA, $P<0.05)$.

\section{PPAR- $\gamma$ Protein Expression}

Lung tissue PPAR- $\gamma$ protein levels in vehicle-treated shunt lambs were lower than in control lambs and RG-treated shunt lambs (Figure 6, ANOVA, $P<0.05$ ).

\section{DISCUSSION}

A vast and expanding body of literature has established the importance of endothelial dysfunction in the pathogenesis

of pulmonary vascular disease. However, endothelial abnormalities are defined broadly. They include alterations in structure, perturbations in the normal production and/or balance of endothelial-derived factors, and functional abnormalities, including increased constriction and/or impaired relaxation. This study used a model of a congenital cardiac defect with increased PBF that mimics the early functional impairment in pulmonary vascular endothelium-dependent relaxation that occurs in infants and children with large leftto-right cardiac shunts, before the development of advanced structural changes and large elevations in PAP. Indeed, in the current era, in which surgical repair in neonates and infants is relatively safe and common, it is these early derangements that account for a substantial portion of the morbidity rather than the advanced structural disease that occurred in previous decades. The primary finding was that chronic treatment with RG prevented impairment in agonist-induced endothelium-dependent pulmonary vascular relaxation in shunt lambs. The association of this finding with an increase in lung tissue NO $x$ levels, increased eNOS activity, increased eNOS phosphorylation (Ser1177), decreased NADPH oxidase activity and subunit expression, and decreased lung tissue superoxide and 3-NT levels suggests two potential mechanisms for this effect: PPAR- $\gamma$ activation may increase bioavailable NO through a decrease in NADPH oxidase activity that results in a decrease in NO scavenging by superoxide, and PPAR- $\gamma$ activation may increase NO production from eNOS by increasing eNOS activity via increased phosphorylation at Ser1177.

In vitro and in vivo studies indicate that PPAR- $\gamma$ signaling can alter oxidative stress and that RG treatment can decrease superoxide production in the systemic vasculature $(9-11,14)$. In the pulmonary vasculature, RG treatment was shown to attenuate pulmonary arterial hypertension and vascular remodeling in chronic-hypoxia mouse models. Mechanisms include alterations in NADPH subunit expression and 

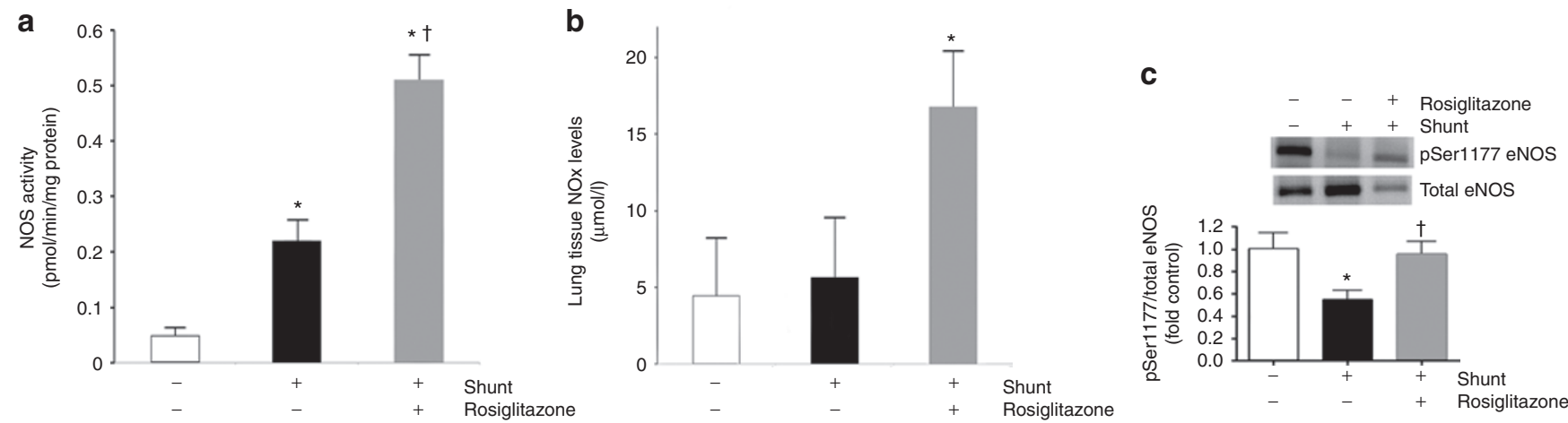

Figure 2. Lung tissue nitric oxide synthase (NOS) activity, NOx levels, and Ser1177 endothelial NOS (eNOS) protein in normal (white bars) and vehicle(black bars) and rosiglitazone (RG)-treated (gray bars) shunt lambs. (a) NOS activity was greater in vehicle-treated shunt lambs than in normal lambs, and greater in RG-treated shunt lambs than in both normal lambs and vehicle-treated shunt lambs. (b) Lung tissue NOx levels were higher in RG-treated shunt lambs than in normal lambs and vehicle-treated shunt lambs. (c) Lung tissue protein expression of Ser1177 eNOS was decreased in vehicle-treated shunt lambs as compared with normal lambs and increased in RG-treated shunt lambs as compared with vehicle-treated shunt lambs. Representative western blots are shown. Densitometric values for Ser1177 eNOS protein are shown relative to normal. $n=5$ for normal group; $n=5$ for vehicle-treated shunt group; $n=6$ for RG-treated shunt group. Values are mean \pm SD. ${ }^{*} P<0.05$ as compared with normal group. $\uparrow P<0.05$ as compared with vehicle-treated shunt group.

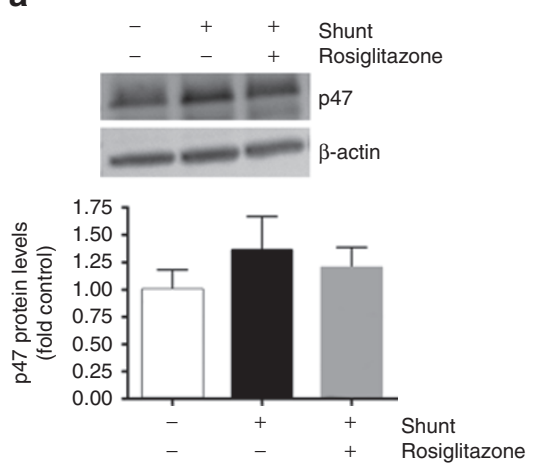

b
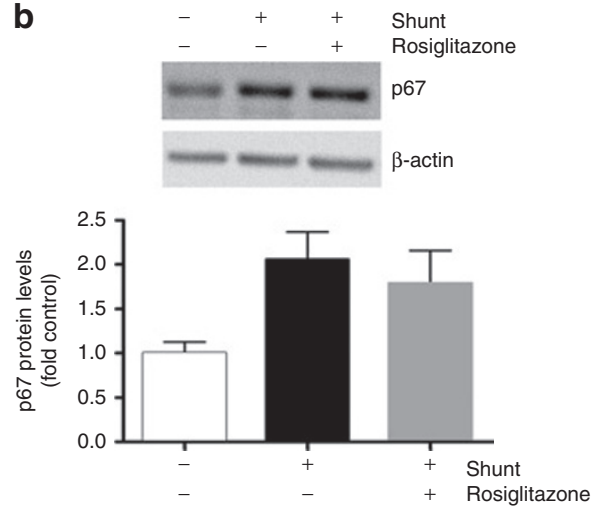

C
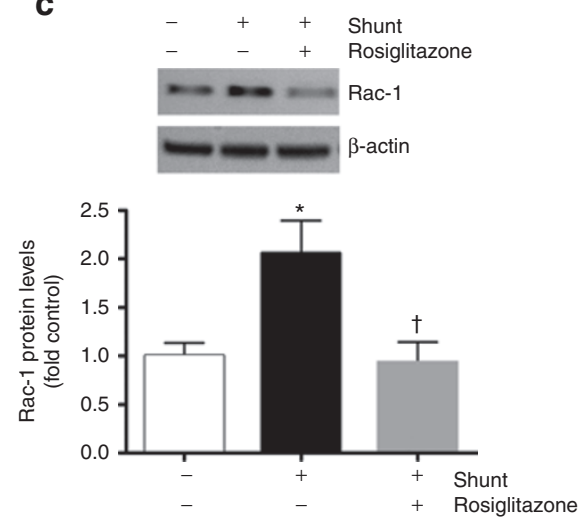

Figure 3. Lung tissue protein levels of nicotinamide adenine dinucleotide phosphate oxidase subunits (a) p47 ${ }^{\text {phox }}$, (b) p67 phox and (c) rac1 in normal (white bars) and vehicle- (black bars) and rosiglitazone (RG)-treated (gray bars) shunt lambs. (a,b) Differences between lung tissue protein expression of $\mathrm{p} 47^{\text {phox }}$ and $p 67^{\text {phox }}$ (ANOVA, $P=0.08$ ) did not reach statistical significance. (c) Lung tissue protein expression of rac 1 was greater in vehicle-treated shunt lambs than in normal lambs, and was lower in RG-treated as compared with vehicle-treated shunt lambs (ANOVA, $P<0.05$ ). Representative western blots are shown. Densitometric values shown relative to normal. $n=5$ for normal group; $n=5$ for vehicle-treated shunt group; $n=6$ for RG-treated shunt group. Values are mean $\pm \mathrm{SD}$. ${ }^{*} P<0.05$ as compared with normal group. $+P<0.05$ as compared with vehicle-treated shunt group.

superoxide levels, regulation of Nox4 expression through NF- $\kappa B$, and a downregulation of PPAR $-\gamma$ through transforming growth factor- $\beta$ (15-17). Thus, the findings of the current study are consistent with this emerging literature but are unique in demonstrating a role for PPAR- $\gamma$ in early selective pulmonary vascular endothelial dysfunction secondary to increased PBF.

In our study, a role for NADPH oxidase is supported by changes in its activity and a decrease in superoxide signaling in the EPR assay with apocynin (an NADPH oxidase inhibitor) in vehicle-treated shunt lambs. Of note, racl protein levels normalized in RG-treated shunt lambs and apocynin had no impact on superoxide levels. Although these data strongly implicate PPAR $-\gamma$ signaling in increased NADPH activity under conditions of increased PBF, the controlling mechanisms require further investigation.
Lung tissue eNOS phosphorylation at Ser1177 decreased in vehicle-treated lambs as compared with normal lambs and normalized in shunt lambs with RG treatment, in association with a significant increase in eNOS activity. Phosphorylation at Ser1177 is known to increase electron flux and enzyme activity of eNOS $(18,19)$. Therefore, the increased lung tissue NOx levels in RG-treated shunt lambs, which were independent of changes in eNOS expression, may relate, in part, to an increase in NO release from endothelial cells apart from, or in addition to, diminished scavenging of NO by superoxide. PBF (with its associated shear forces) is a well-established and strong stimulus of NO release from eNOS (20). Therefore, the increases in $\mathrm{NO} x$ and eNOS activity in shunt lambs as compared with normal lambs were expected and consistent with previous studies (1). Alterations in bioavailable NO cannot be simply understood by analysis of lung tissue NOx levels. Rather, the demonstration 


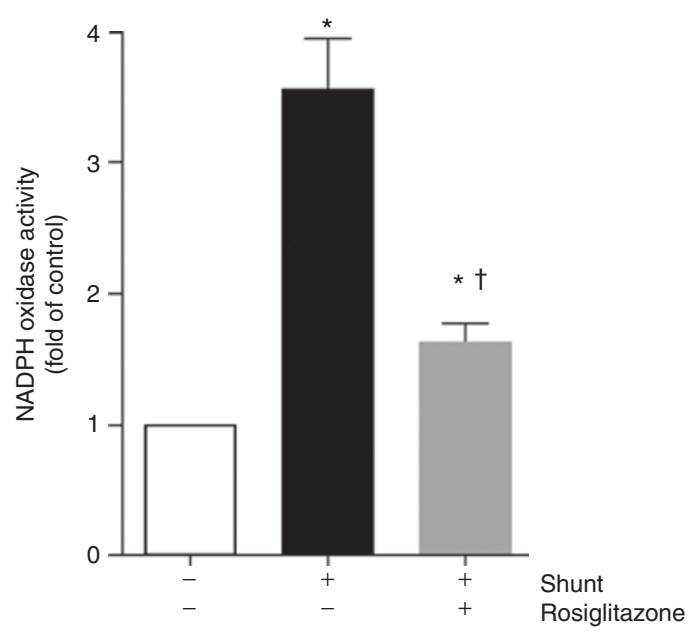

Figure 4. Lung tissue nicotinamide adenine dinucleotide phosphate (NADPH) oxidase activity in normal (white bar) and vehicle- (black bar) and rosiglitazone-treated (gray bar) shunt lambs. Lung tissue NADPH oxidase activity was measured by a low concentration-based lucigenin $(5 \mu \mathrm{mol} / \mathrm{l})$ assay. Control activity was arbitrarily set at $100 \% . n=4$ for each group. Values are mean $\pm S D * P<0.05$, as compared with normal group. $+P<0.05$ as compared with vehicle-treated shunt group.

of impaired agonist-induced selective endothelium-dependent pulmonary relaxation is of primary relevance. However, we have previously demonstrated that impaired bioavailable $\mathrm{NO}$ can be understood by analyzing $\mathrm{NO} x$ levels relative to eNOS activity. We have shown previously that shunt lambs develop a progressive decrease in NOx levels relative to eNOS activity as compared with age-matched normal lambs from 2 to 8 wk of age (1). In the current study, NOS activity was increased in shunt lambs compared with normal lambs, as expected, and NOx levels relative to eNOS activity were greater in normal lambs as compared with shunt lambs. Of note, RG treatment resulted in a marked increase in NOx and eNOS activity in shunt lambs.

Superoxide reacts avidly with NO to produce peroxynitrite. The determination of peroxynitrite levels in vivo is challenging. Peroxynitrite readily nitrates protein tyrosine residues, and thus quantification of nitrotyrosine (3-NT) provides an indirect measure of peroxynitrite levels. Consistent with previous studies, we found an increase in 3-NT levels in vehicle-treated shunt lambs as compared with normal lambs. Moreover, consistent with our hypothesis that RG treatment would decrease oxidative stress in shunt lambs, we found the RG-treated shunt lambs had 3-NT levels that were lower than those of vehicletreated shunt lambs and similar to those of normal lambs.

Of note, we found that PPAR- $\gamma$ expression was decreased in vehicle-treated shunt lambs as compared with normal lambs and was increased in RG-treated shunt lambs. Little is known about the regulation of PPAR- $\gamma$ expression in lung tissue in either health or disease. A recent study demonstrated that NO can activate PPAR- $\gamma$ via a p38 mitogen-activated protein kinase pathway, which is intriguing given the increased $\mathrm{NO} x$ levels in RG-treated shunt lambs (21). However, whether cross talk between NO and PPAR- $\gamma$ results in increased PPAR- $\gamma$ expression in lung tissue is unclear. In addition, a

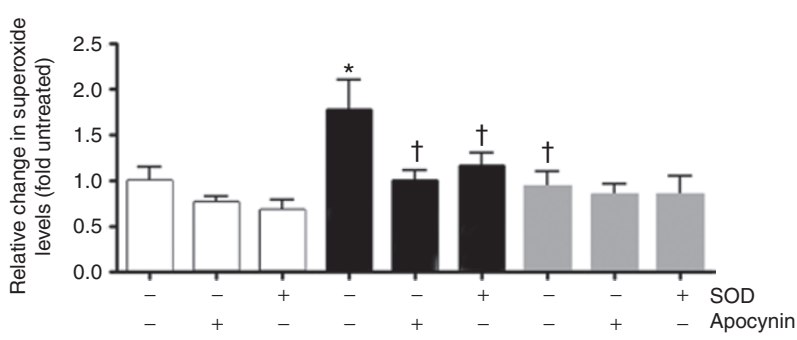

b

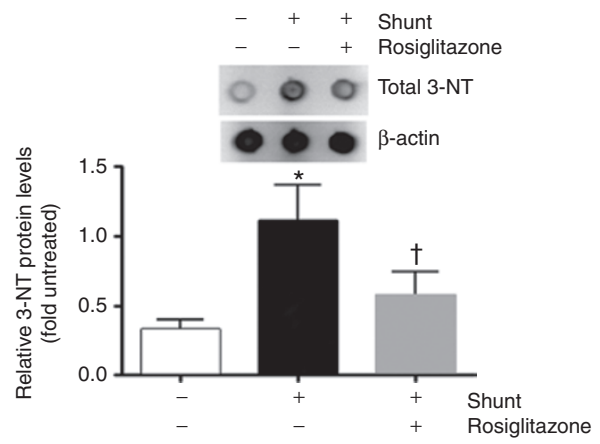

Figure 5. Superoxide and 3-nitrotyrosine (3-NT) protein levels in lung tissue from normal (white bars) and vehicle- (black bars) and rosiglitazone (RG)-treated (gray bars) shunt lambs. (a) Superoxide levels estimated by electron paramagnetic resonance (EPR). Superoxide levels were higher in vehicle-treated shunt lambs than in normal lambs, and lower in RG-treated than in vehicle-treated lambs. Specificity of the EPR assay for superoxide was confirmed by a reduction in the waveform amplitude with the addition of SOD to the samples in vehicle-treated shunt lambs. The addition of apocynin (an NADPH oxidase inhibitor) to the samples resulted in no change in EPR amplitude of normal and RG-treated lambs but a $\sim 37 \%$ signal reduction in vehicle-treated lambs. (b) Lung tissue 3-NT levels were increased in vehicle-treated shunt lambs as compared with normal lambs, and decreased in RG-treated as compared with vehicle-treated shunt lambs. Representative western blots are shown. $n=5$ for normal group; $n=5$ for vehicle-treated shunt group; $n=6$ for RG-treated shunt group. Values are mean $\pm \mathrm{SD}$. ${ }^{*} P<0.05$ as compared with normal group. $+P<0.05$ as compared with vehicle-treated shunt group. NADPH, nicotinamide adenine dinucleotide phosphate; SOD, superoxide dismutase.

whether PPAR- $\gamma$ activation, from RG-treatment, alone accounted for the preservation in endothelium-dependent pulmonary vascular relaxation or whether the increase in PPAR- $\gamma$ expression was necessary remains an interesting but unanswered question.

We conclude that PPAR- $\gamma$ activation with chronic RG treatment attenuates the impairment in agonist-induced endothelium-dependent pulmonary vascular relaxation in 4 -wk-old lambs with a model of increased PBF. We propose that an increase in bioavailable NO underlies this effect, and that it may be mediated by two potential mechanisms: a decrease in NADPH oxidase activity that results in lower superoxide levels with less NO scavenging, and an increase in NO production secondary to increased eNOS activity due to increased phosphorylation at Ser1177. The potential ability to use PPAR- $\gamma$ agonists to diminish endothelial injury and/or dysfunction in infants and children with common congenital cardiac defects that result in increased PBF is exciting given that this class of medications is currently commercially available for clinical 

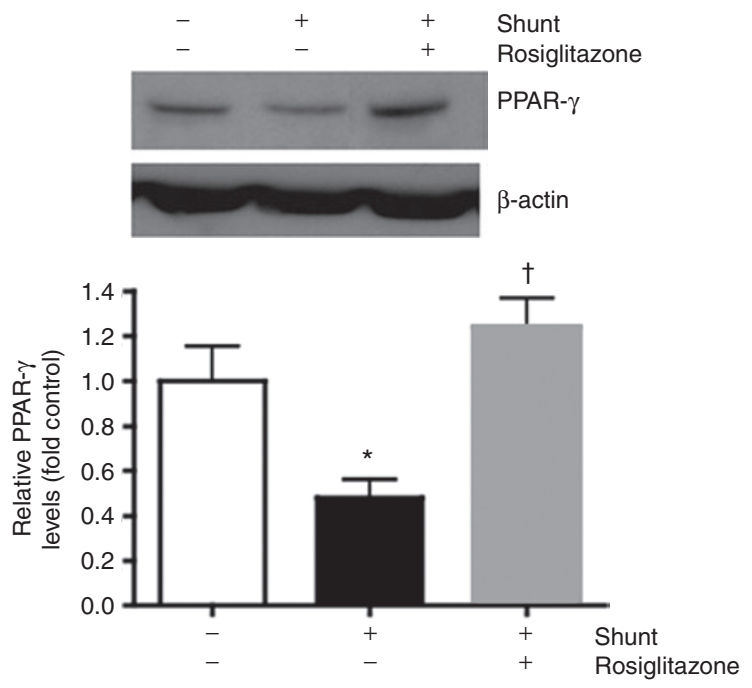

Figure 6 . Lung tissue protein expression of peroxisome proliferatoractivated receptor (PPAR- $\gamma$ ) in normal (white bar) and vehicle- (black bar) and rosiglitazone (RG)-treated (gray bar) shunt lambs. PPAR- $\gamma$ was decreased in vehicle-treated shunt lambs as compared with normal lambs and increased in RG-treated shunt lambs as compared with vehicle-treated shunt lambs. Representative western blots are shown. Densitometric values for PPAR- $\gamma$ protein are shown relative to normal. $n=5$ for normal group; $n=5$ for vehicle-treated shunt group; $n=6$ for RG-treated shunt group. Values are mean \pm SD. ${ }^{*} P<0.05$ as compared with normal group. $+P<0.05$ as compared with vehicle-treated shunt group.

use. Therefore, we believe that further investigation of these pathways is warranted.

\section{METHODS}

\section{Surgical Preparation}

A total of 11 mixed-breed Western pregnant ewes (137-141 d gestation, term $=145 \mathrm{~d}$ ) were anesthetized. Fetal exposure was obtained through the pregnant horn of the uterus and a left lateral thoracotomy was performed on the fetal lamb. With the use of side biting vascular clamps, an $8.0-\mathrm{mm}$ vascular graft was anastomosed between the ascending aorta and main pulmonary artery of the fetal lambs. This procedure was previously described in detail (1).

Four weeks after spontaneous delivery, shunt lambs were anesthetized and catheters were placed into the right and left atrium and main pulmonary artery. An ultrasonic flow probe (Transonics Systems, Ithaca, NY) was placed around the left pulmonary artery to measure PBF. Arterial blood and lung biopsies were obtained. In addition, using identical anesthesia, arterial blood and lung tissue were harvested from five normal, nonshunted, 4 -wk-old lambs for comparisons of biochemical data with those of vehicle- and RG-treated shunt lambs. Arterial blood and lung pieces were processed as previously described in detail (1).

At the end of the protocol, all lambs were killed with a lethal injection of sodium pentobarbital followed by bilateral thoracotomy as described in the National Institutes of Health Guidelines for the Care and Use of Laboratory Animals. All protocols and procedures were approved by the Committee on Animal Research of the University of California, San Francisco.

\section{Drug Protocol}

Beginning immediately after birth, lambs were treated with either RG (GlaxoSmithKline, Brentford, UK, $n=6,3 \mathrm{mg} / \mathrm{kg} / \mathrm{d}$ ) or empty gelatin capsules ( $n=5$, vehicle control). The drug or vehicle capsules were administered orally once daily for a 4 -wk period. The number of vehicle capsules administered was increased to match the upwardly adjusted weight-based dosing of RG.

\section{Measurements}

Pulmonary and systemic arterial, and right and left atrial pressures, heart rate, and PBF were measured. All hemodynamic variables were measured continuously using the Gould Ponemah Physiology Platform (Version 4.2) and Acquisition Interface (Model ACG-16, Gould, Cleveland, $\mathrm{OH}$ ). Blood gases and $\mathrm{pH}$ were measured, and PVR was calculated using standard formulae. Shunt fraction (pulmonary flow/systemic flow) was determined using the Fick principle. These procedures were previously described in detail (1).

\section{Pulmonary Vascular Reactivity}

Pulmonary vascular responses were assessed after the administration of ACh and inhaled NO. Lambs were instrumented as above and allowed to rest for a minimum of $30 \mathrm{~min}$. Mechanical ventilation was adjusted to maintain $\mathrm{pCO}_{2}$ between 35 and $40 \mathrm{~mm} \mathrm{Hg}$ and $\mathrm{pH}$ between 7.35 and 7.40. Sodium bicarbonate was administered to correct metabolic acidosis if it occurred. The inspired oxygen concentration was maintained at $21 \%$. Baseline hemodynamics and PBF were recorded. In random order, ACh $(1 \mu \mathrm{g} / \mathrm{kg})$ or inhaled NO $(40 \mathrm{ppm})$ was administered. ACh chloride (Iolab, Claremont, CA) was diluted in sterile $0.9 \%$ saline and delivered by rapid injection into the pulmonary artery. Inhaled NO was delivered to the inspiratory limb of the respiratory circuit (Inovent, Ohmeda, Liberty, NJ), and continued for $10 \mathrm{~min}$. The inspired concentrations of NO and nitrogen dioxide were continuously quantified by electrochemical methodology (Inovent, Ohmeda, Liberty, NJ). The hemodynamic variables were monitored and recorded continuously. A minimum of $30 \mathrm{~min}$ separated the administration of $\mathrm{ACh}$ and inhaled $\mathrm{NO}$, and the second agent was not given until hemodynamics returned to baseline.

\section{Preparation of Protein Extracts and Western Blot Analysis}

Lung protein extracts were prepared and western blot analysis was performed as previously described $(1,22)$. Briefly, western blot analysis was performed with a 1:2,500 dilution of the NOS antiserum; 1:100 dilution of PPAR- $\gamma ; 1: 500$ dilution of Rac1, p47 $7^{\text {phox }}$, and $\mathrm{p} 67^{\text {phox; }}$ 1:1,000 dilution of 3-NT antibody, and antiphospho Ser1177 eNOS; or a $1: 10,000$ dilution of $\beta$-actin, washed with tris-buffered saline containing $0.1 \%$ Tween, and then incubated with a goat antimouse immunoglobulin $\mathrm{G}$ horseradish peroxidase. After washing, the protein bands were visualized with chemiluminescence using a Kodak Digital Science Image Station (NEN Life Science Products, Boston, $\mathrm{MA}$ ) and analyzed using the KED-1 software (KDE, Brighton, MA). All captured and analyzed images were determined to be in the dynamic range of the system. The eNOS, Rac1, p47 $7^{\text {phox }}$, and PPAR- $\gamma$ antisera were obtained from Transduction Laboratories (Lexington, KY); 3-NT antibody was obtained from Calbiochem (San Diego, CA); and antiphospho Ser1177 eNOS was obtained from Cell Signaling Technology (Danvers, MA). To normalize for protein loading, blots were reprobed with $\beta$-actin.

\section{Measurement of $\mathrm{NO}$}

To quantify bioavailable NO, NO and its metabolites were determined in lung tissue as we have previously described $(1,23,24)$. The sensitivity is $1 \times 10^{-12}$ moles, with a concentration range of $1 \times 10^{-9}$ to $1 \times 10^{-3}$ molar of nitrate.

\section{Assay for NOS Activity}

NOS activity was determined using the conversion of $3 \mathrm{H}$-L-arginine to $3 \mathrm{H}$-L-citrulline as described by Bush (25) and as we have previously described in detail (1). All activities were normalized to the amount of protein in each lysate. To determine the potential contribution of inducible NOS to total NOS activity, assays were repeated without calcium supplementation.

\section{Lung Tissue NADPH Oxidase Assay}

Lung tissue from normal lambs and vehicle- and RG-treated shunt lambs was collected and homogenated with Tris-sucrose buffer $(10 \mathrm{mmol} / \mathrm{l}$ Tris base (Fischer, Fairlawn NJ)), $340 \mathrm{mmol} / \mathrm{l}$ sucrose (Mallinkrodt Baker, Philipsburg, NJ), 1 mmol/l EDTA (Mallinkrodt 
Baker), and $10 \mu \mathrm{g} / \mathrm{ml}$ protease inhibitor mixture (Sigma, St. Louis, MO). The homogenate protein concentration was measured. NADPH oxidase activity was measured by a luminescence assay in the reaction buffer with $5 \mu \mathrm{mol} / \mathrm{l}$ lucigenin, $1 \mathrm{mmol} / \mathrm{l} \mathrm{EGTA}$, and $50 \mathrm{mmol} / \mathrm{l}$ phosphate buffer, $\mathrm{pH}$ 7.0. A total of $100 \mu \mathrm{g}$ of homogenate protein $+100 \mu \mathrm{mol} / \mathrm{l}$ NADPH as substrate (Sigma) was added to an $8 \mathrm{~mm}$ test tube with $500 \mu$ of reaction buffer, then incubated at $37^{\circ} \mathrm{C}$ for $5 \mathrm{~min}$. Photon emission was measured at $15 \mathrm{~s}$ in a luminometer (model TD-20/20; Turner Designs, Sunnyvale, CA) $(26,27)$.

\section{Superoxide Quantitation}

Superoxide levels in lung tissue were estimated by EPR assay using the spin-trap compound CM in the presence and absence of polyethylene glycol-superoxide dismutase, as we have previously described $(1,13)$. To determine the specificity of the detected EPR signal, additional sample groups were immersed in EPR buffer supplemented with $100 \mathrm{U} / \mathrm{ml}$ of the membrane-permeable form of superoxide dismutase (polyethylene glycol-conjugated superoxide dismutase). In addition, to determine the relative contribution of NADPH oxidase activity to superoxide production, equivalent samples were preincubated in 100 $\mu \mathrm{mol} / \mathrm{l}$ apocynin (Sigma, St. Louis, MO), an NADPH oxidase inhibitor, as we have previously described $(1,28)$. Samples were analyzed for protein content using Bradford analysis (Bio-Rad, Hercules, CA). Sample volumes were then adjusted with EPR buffer and $25 \mathrm{mg} / \mathrm{ml}$ $\mathrm{CM}$ hydrochloride to achieve equal protein content and a final CM concentration of $5 \mathrm{mg} / \mathrm{ml}$. Samples were analyzed with a MiniScope MS200 ESR (Magnettech, Berlin, Germany). Resulting EPR spectra were analyzed using ANALYSIS v.2.02 software (Magnettech), whereby the EPR maximum and minimum spectral amplitudes for the CM superoxide spin-trap product waveform were quantified.

\section{Statistical Analysis}

Statistical calculations were performed using the GraphPad Prism V. 4.01 software (GraphPad Software, La Jolla, CA). The mean \pm SD or SE was calculated for all samples, and significance was determined either by the unpaired $t$-test or ANOVA. For ANOVA, Newman-Keuls post hoc testing was also used.

\section{ACKNOWLEDGMENTS}

The authors thank Michael Johengen and Cynthia Harmon for their expert technical assistance.

\section{STATEMENT OF FINANCIAL SUPPORT}

This research was supported in part by National Institutes of Health grants HD047349 (to P.O.), HL60190 (to S.M.B.), HL67841 (to S.M.B.), HL72123 (to S.M.B.), HL70061 (to S.M.B.), HL084739-03 (to S.M.B.), HD057406 (to S.M.B.), and HL61284 (to J.R.F.) and a Transatlantic Network Development grant from the LeDucq Foundation (to S.M.B. and J.R.F.).

Disclosure: The authors declare no conflict of interest.

\section{REFERENCES}

1. Oishi PE, Wiseman DA, Sharma S, et al. Progressive dysfunction of nitric oxide synthase in a lamb model of chronically increased pulmonary blood flow: a role for oxidative stress. Am J Physiol Lung Cell Mol Physiol 2008;295:L756-66.

2. Lakshminrusimha $\mathrm{S}$, Wiseman D, Black SM, et al. The role of nitric oxide synthase-derived reactive oxygen species in the altered relaxation of pulmonary arteries from lambs with increased pulmonary blood flow. Am J Physiol Heart Circ Physiol 2007;293:H1491-7.

3. Grobe AC, Wells SM, Benavidez E, et al. Increased oxidative stress in lambs with increased pulmonary blood flow and pulmonary hypertension: role of NADPH oxidase and endothelial NO synthase. Am J Physiol Lung Cell Mol Physiol 2006;290:L1069-77.

4. Kersten S, Desvergne B, Wahli W. Roles of PPARs in health and disease. Nature 2000;405:421-4.

5. Ameshima S, Golpon H, Cool CD, et al. Peroxisome proliferator-activated receptor gamma (PPARgamma) expression is decreased in pulmonary hypertension and affects endothelial cell growth. Circ Res 2003;92:1162-9.

6. Nisbet RE, Sutliff RL, Hart CM. The role of peroxisome proliferator-activated receptors in pulmonary vascular disease. PPAR Res 2007;2007:18797.
7. Calnek DS, Mazzella L, Roser S, Roman J, Hart CM. Peroxisome proliferator-activated receptor gamma ligands increase release of nitric oxide from endothelial cells. Arterioscler Thromb Vasc Biol 2003;23:52-7.

8. Polikandriotis JA, Mazzella LJ, Rupnow HL, Hart CM. Peroxisome proliferator-activated receptor gamma ligands stimulate endothelial nitric oxide production through distinct peroxisome proliferator-activated receptor gamma-dependent mechanisms. Arterioscler Thromb Vasc Biol 2005;25:1810-6.

9. Inoue I, Goto S, Matsunaga T, et al. The ligands/activators for peroxisome proliferator-activated receptor alpha (PPARalpha) and PPARgamma increase $\mathrm{Cu} 2+, \mathrm{Zn} 2+$-superoxide dismutase and decrease p22phox message expressions in primary endothelial cells. Metab Clin Exp 2001;50:3-11.

10. Hwang J, Kleinhenz DJ, Lassègue B, Griendling KK, Dikalov S, Hart $\mathrm{CM}$. Peroxisome proliferator-activated receptor-gamma ligands regulate endothelial membrane superoxide production. Am J Physiol Cell Physiol 2005;288:C899-905.

11. Iglarz M, Touyz RM, Amiri F, Lavoie MF, Diep QN, Schiffrin EL. Effect of peroxisome proliferator-activated receptor-alpha and -gamma activators on vascular remodeling in endothelin-dependent hypertension. Arterioscler Thromb Vasc Biol 2003;23:45-51.

12. Tian J, Smith A, Nechtman J, et al. Effect of PPARgamma inhibition on pulmonary endothelial cell gene expression: gene profiling in pulmonary hypertension. Physiol Genomics 2009;40:48-60.

13. Wiseman DA, Wells SM, Hubbard M, Welker JE, Black SM. Alterations in zinc homeostasis underlie endothelial cell death induced by oxidative stress from acute exposure to hydrogen peroxide. Am J Physiol Lung Cell Mol Physiol 2007;292:L165-77.

14. Bagi Z, Koller A, Kaley G. PPARgamma activation, by reducing oxidative stress, increases NO bioavailability in coronary arterioles of mice with Type 2 diabetes. Am J Physiol Heart Circ Physiol 2004;286:H742-8.

15. Nisbet RE, Bland JM, Kleinhenz DJ, et al. Rosiglitazone attenuates chronic hypoxia-induced pulmonary hypertension in a mouse model. Am J Respir Cell Mol Biol 2010;42:482-90.

16. Gong K, Xing D, Li P, et al. Hypoxia induces downregulation of PPAR- $\gamma$ in isolated pulmonary arterial smooth muscle cells and in rat lung via transforming growth factor- $ß$ signaling. Am J Physiol Lung Cell Mol Physiol 2011;301:L899-907.

17. Lu X, Murphy TC, Nanes MS, Hart CM. PPAR\{gamma\} regulates hypoxia-induced Nox4 expression in human pulmonary artery smooth muscle cells through NF-\{kappa\}B. Am J Physiol Lung Cell Mol Physiol 2010;299:L559-66.

18. Harris MB, Ju H, Venema VJ, et al. Reciprocal phosphorylation and regulation of endothelial nitric-oxide synthase in response to bradykinin stimulation. J Biol Chem 2001;276:16587-91.

19. Shi Y, Baker JE, Zhang C, Tweddell JS, Su J, Pritchard KA Jr. Chronic hypoxia increases endothelial nitric oxide synthase generation of nitric oxide by increasing heat shock protein 90 association and serine phosphorylation. Circ Res 2002;91:300-6.

20. Dimmeler S, Fleming I, Fisslthaler B, Hermann C, Busse R, Zeiher AM. Activation of nitric oxide synthase in endothelial cells by Akt-dependent phosphorylation. Nature 1999;399:601-5.

21. Ptasinska A, Wang S, Zhang J, Wesley RA, Danner RL. Nitric oxide activation of peroxisome proliferator-activated receptor gamma through a p38 MAPK signaling pathway. FASEB J 2007;21:950-61.

22. Wedgwood S, McMullan DM, Bekker JM, Fineman JR, Black SM. Role for endothelin-1-induced superoxide and peroxynitrite production in rebound pulmonary hypertension associated with inhaled nitric oxide therapy. Circ Res 2001;89:357-64.

23. Black SM, Heidersbach RS, McMullan DM, Bekker JM, Johengen MJ, Fineman JR. Inhaled nitric oxide inhibits NOS activity in lambs: potential mechanism for rebound pulmonary hypertension. Am J Physiol 1999;277(5 Pt 2):H1849-56.

24. McMullan DM, Bekker JM, Parry AJ, et al. Alterations in endogenous nitric oxide production after cardiopulmonary bypass in lambs with normal and increased pulmonary blood flow. Circulation 2000;102:19:Suppl 3:III172-8. 
25. Bush PA, Gonzalez NE, Ignarro LJ. Biosynthesis of nitric oxide and citrulline from $\mathrm{L}$-arginine by constitutive nitric oxide synthase present in rabbit corpus cavernosum. Biochem Biophys Res Commun 1992;186:308-14.

26. Griendling KK, Minieri CA, Ollerenshaw JD, Alexander RW. Angiotensin II stimulates NADH and NADPH oxidase activity in cultured vascular smooth muscle cells. Circ Res 1994;74:1141-8.
27. Abid MR, Spokes KC, Shih SC, Aird WC. NADPH oxidase activity selectively modulates vascular endothelial growth factor signaling pathways. J Biol Chem 2007;282:35373-85.

28. Sharma S, Kumar S, Wiseman DA, et al. Perinatal changes in superoxide generation in the ovine lung: alterations associated with increased pulmonary blood flow. Vascul Pharmacol 2010;53:38-52. 